This item was submitted to Loughborough's Research Repository by the author.

Items in Figshare are protected by copyright, with all rights reserved, unless otherwise indicated.

\title{
Direct ink writing of bismuth molybdate microwave dielectric ceramics
}

PLEASE CITE THE PUBLISHED VERSION

https://doi.org/10.1016/j.ceramint.2020.11.102

PUBLISHER

Elsevier

VERSION

AM (Accepted Manuscript)

PUBLISHER STATEMENT

This paper was accepted for publication in the journal Ceramics International and the definitive published version is available at https://doi.org/10.1016/j.ceramint.2020.11.102.

\section{LICENCE}

CC BY-NC-ND 4.0

\section{REPOSITORY RECORD}

Goulas, Athanasios, George Chi-Tangyie, Shiyu Zhang, Dawei Wang, Annapoorani Ketharam, Vaidhy Vaidhyanathan, lan Reaney, et al.. 2020. "Direct Ink Writing of Bismuth Molybdate Microwave Dielectric Ceramics". Loughborough University. https://hdl.handle.net/2134/13239038.v1. 


\title{
Direct ink writing of bismuth molybdate microwave dielectric ceramics
}

\author{
*Athanasios Goulas', George Chi-Tangyie 2 , Shiyu Zhang ${ }^{1}$, Dawei Wang ${ }^{3}$, Annapoorani Ketharam ${ }^{2}$, \\ Bala Vaidhyanathan ${ }^{2}$, Ian M. Reaney ${ }^{3}$, Darren A. Cadman ${ }^{1}$, Will Whittow ${ }^{1}$, John (Yiannis) C. \\ Vardaxoglou ${ }^{1}$, Daniel S. Engstrøm ${ }^{1}$
}

\footnotetext{
${ }^{1}$ Wolfson School of Mechanical, Electrical and Manufacturing Engineering, Loughborough University, LE11 3TU, United Kingdom.

2 Department of Materials, Loughborough University, Loughborough, LE11 3TU, United Kingdom.

${ }^{3}$ Department of Materials Science and Engineering, University of Sheffield, Sheffield, S1 3JD, United Kingdom.
}

\section{*a.goulas@lboro.ac.uk}

\section{ABSTRACT}

Additive manufacturing via direct ink writing and microwave dielectric characterisation of commercially produced low sintering temperature bismuth molybdenum oxide ceramics, have been both performed for the first time, following a powder-to-product holistic approach. We demonstrated that direct ink writing is an excellent candidate for producing dielectric substrates to be used for wireless telecommunication applications operating at microwave (MW) frequencies, with great repeatability and properties comparable to ceramics fabricated via conventional processing routes. The optimum density (relative density of $\rho_{r} \approx 93 \%$ ) of the 3D printed test samples was obtained by sintering at $660^{\circ} \mathrm{C}$ for 2 hours, resulting in a relative permittivity $\varepsilon_{r}=35.7$, dielectric loss tan $\delta=0.0004$ and microwave quality factor $Q \times f=14,928 \mathrm{GHz}$. Sintering at higher temperatures promoted a porosity increase due to mismatching grain growth mechanisms and phase decomposition, that collectively hindered the test samples' microwave dielectric performance in terms of achievable relative permittivity $\left(\varepsilon_{r}\right)$ and dielectric loss $(\tan \delta)$.

Keywords: direct ink writing; LTCC; bismuth molybdenum oxide; microwave ceramics 


\section{INTRODUCTION}

Microwave (MW) dielectric ceramics are amongst the most commonly used materials in the modern telecommunication engineering world. Example applications include filters resonance devices, dielectric substrates and capacitors [1]. Typical ceramic components for such applications are manufactured via traditional sintering routes, that require densification temperatures that often exceed $1000^{\circ} \mathrm{C}[2-4]$. The introduction of low sintering temperature co-fired ceramics (LTCCS) endeavours to revolutionise the way modern components and devices are produced [5-7]. LTCCs can be densified at temperatures well below $1000^{\circ} \mathrm{C}$ and allow co-sintering with low cost electrode materials, such as silver, copper or gold [8-11]. This will benefit electronics manufacture by reducing the associated carbon footprint, since lower processing temperatures would require less energy consumption and $\mathrm{CO}_{2}$ emissions [12].

For radiofrequency (RF) devices operating at MW frequencies, LTCCS should exhibit a combination of dielectric properties, such as high-quality factor $(Q \times f>3000 \mathrm{GHz})$, low dielectric loss $(\tan \delta)$ and medium relative permittivity values $\left(10<\varepsilon_{r}<50\right)$ [13]. The ceramic compounds of the $\mathrm{Bi}_{2} \mathrm{O}_{3}-\mathrm{MoO}_{3}$ binary system [14] have previously been discussed as promising candidates for producing LTCC components, as they can be densified below $700^{\circ} \mathrm{C}$ with microwave dielectric properties of relative permittivity $\varepsilon_{r} \approx 17-40$ and $Q \times f \approx 12,500-21,800 \mathrm{GHz}[11,15]$. An extensive list of the microwave dielectric properties of the pure phases that exist in the $\mathrm{Bi}_{2} \mathrm{O}_{3}-\mathrm{MoO}_{3}$ system can be found in the work of Zhou et al. [16]. Note, all reported properties have been extracted from measurements using near full density pressed pellets (<99\%), that exhibit bulk-material properties.

Additive manufacturing (AM) has been acknowledged as a promising enabler in manufacturing of ceramic components $[17,18]$. AM and its associated processes, can repeatably produce parts with performance comparable to the ones made via conventional processing, together with a greater design freedom that can deliver topologically optimised structures, functionally graded properties [19] and also multi-material printing $[20,21]$ for producing intergraded circuitry and functional devices 
[22]. However, there are very few examples in the literature, where AM of LTCCs for MW applications is being reported.

Väätäjä et al., reported the additive manufacture of $\mathrm{Li}_{2} \mathrm{MoO}_{4} \mathrm{MW}$ ceramic, using $\mathrm{DWI}$ without the need of a sintering stage [23]. Printed and dried samples achieved $\varepsilon_{r}=4.4$ and $\tan \delta=0.0006$. The authors have recently demonstrated the additive manufacture of $\mathrm{Ag}_{2} \mathrm{Mo}_{2} \mathrm{O}_{7}$, an ultra-low sintering temperature and low loss MW ceramic compound, using the DIW technique [20]. Measurements from printed and fired test samples marked $\varepsilon_{r}=13.45, \tan \delta=0.0005, Q x f=17.056$ and $\tau_{f}=-121 \mathrm{ppm} /{ }^{\circ} \mathrm{C}$. A series of metal/ceramic patch antennas were also shown, highlighting the potential of DIW to be used for making functional devices via dual-material printing.

Additively manufactured components do not always attain bulk material properties due to processspecific limitations, such as non-continuous material deposition that inherently leads to porosity, which limits the achievable relative permittivity and affects repeatability of the fabrication method [24].

This study reports for the first time the additive manufacture of $\mathrm{Bi}_{2} \mathrm{Mo}_{2} \mathrm{O}_{9}$ ceramics, by using direct ink writing; a material extrusion additive manufacturing process. The effect of thermal post processing conditions on the physical, microstructural and microwave dielectric properties is discussed. 


\section{MATERIALS \& METHODS}

\subsection{Materials}

A high-purity and commercially available bismuth molybdenum oxide $\mathrm{Bi}_{2} \mathrm{Mo}_{2} \mathrm{O}_{9}(\mathrm{BMO})$ powder $(99.8$ $\%$, American Elements, Los Angeles, CA, USA) was obtained, with an average particle size below 10 $\mu \mathrm{m}$.

\subsection{Ceramic paste formulation}

A binder mix consisting of ethylene glycol diacetate ( $7.1 \mathrm{wt. \% ,} \mathrm{Sigma} \mathrm{Aldrich,} \mathrm{UK)} \mathrm{as} \mathrm{dispersant,} \mathrm{ethyl}$ cellulose ( 2 wt.\%, Sigma Aldrich, UK) and propylene carbonate (1.9 wt.\%, Sigma Aldrich, Dorset, UK) as viscosity modifier and binder, diisononyl phthalate (2.7 wt.\%, Sigma Aldrich, Dorset, UK) as plasticiser, and ammonium lauryl sulphate ( $<0.5$ wt.\%, Sigma Aldrich, Dorset, UK) as surfactant was prepared. The BMO powder was slowly incorporated into the binder mix followed by mixing and then topped with de-ionised water. The paste was homogenised three times using a planetary mixer (Thinky ARM 310, Thinky Inc., Laguna Hills, California USA) at $1500 \mathrm{rpm}$ with 2 mins pulses for a total duration of 2 hours. The total solids content in the paste was $85 \mathrm{wt} . \%$.

\subsection{Direct ink writing and thermal post-processing}

All additively manufactured test samples were made using a multi-process additive manufacturing kit (High-Resolution Engine, Hyrel3D, Norcross, GA, USA), equipped with a syringe dispensing module (SDS-5, Hyrel3D, Norcross, GA, USA), using 5 ml luer-lock syringes (Becton Dickinson, Franklin Lakes, New Jersey, USA) and $0.5 \mathrm{~mm}$ metallic needles of $18.25 \mathrm{~mm}$ in length (Adhesive Dispensing, Milton Keynes, United Kingdom). A combination of printing speed of $5 \mathrm{~mm} / \mathrm{s}$, layer thickness of $0.2 \mathrm{~mm}, 0.45$ $\mathrm{mm}$ hatch spacing; providing a $10 \%$ overlap of the extruded filaments, and a constant positive displacement value of 90 pulses per microlitre, were used to print cylindrical test samples of $10 \mathrm{~mm}$ in diameter and $4 \mathrm{~mm}$ thickness; as shown in Figure 1. The test samples were first modelled using CAD and G-code for printing was generated using Hyrel3D's inbuilt slicing software. All test samples 
were printed on top of smooth surface alumina substrates of $50 \times 50 \times 1 \mathrm{~mm}$ (PI-KEM, Tamworth, Staffordshire, UK).

The 3D printed samples were left to dry at room temperature for a minimum of 24 hours. The samples were thermally debinded in a furnace using a ramp rate of $1^{\circ} \mathrm{C} / \mathrm{min}$ to $500^{\circ} \mathrm{C}$, whilst holding at $100^{\circ} \mathrm{C}$, $200^{\circ} \mathrm{C}, 300^{\circ} \mathrm{C}, 400^{\circ} \mathrm{C}$ and $500^{\circ} \mathrm{C}$ for 2 hours each. The binder removal process was slow in order to avoid the cracking and/or warpage of the 3D printed samples. The debinded samples were sintered between $640-670^{\circ} \mathrm{C}$ for 2 hours with heating and cooling rates of $3^{\circ} \mathrm{C} / \mathrm{min}$.

\subsection{Characterisation methods}

The particle size of the as-received powder was confirmed using laser diffraction (Scirocco 2000, Mastersizer, UK). Particle size results are reported as an average of three different powder samples, together with standard deviation.

The phase structure and purity of the BMO powder together with any potential phase changes during sintering, were investigated using X-Ray diffraction (D2 Phaser, Bruker AXS, Karlsruhe, Germany) using CuK $_{\alpha}$ radiation at $\lambda=1.54054 \AA$, operating at $30 \mathrm{kV}$ and $10 \mathrm{~mA}$. A $1 \mathrm{~mm}$ divergence and a $3 \mathrm{~mm}$ antiscatter slits were used. Diffraction patterns were collected in the $10-60^{\circ} 2 \vartheta$ interval, using a $0.02^{\circ}$ step size and 15/min sample rotation. Collected data were analysed using Bruker's proprietary software (DIFFRAC.EVA 5.2, Bruker AXS, Karlsruhe, Germany).

The density of the sintered samples was measured using the Archimedes principle. Densities are reported as an average of three different 3D printed samples, together with the standard deviation.

The impact of sintering temperature on the ceramic microstructure was assessed using scanning electron microscopy (SEM) (TM3030, Hitachi High Energy Technologies, etc.). 3D printed test samples were embedded in epoxy resin (EpoThin2, Buehler, Illinois, USA) and prepared using a standard metallographic regime; ground using silicon carbide paper of P1200 grit size, followed by a polishing stage using a polishing cloth and a $0.05 \mu \mathrm{m}$ alumina suspension. To prevent charging during SEM, 
samples were sputter coated with a gold/palladium alloy in an 80:20 wt.\% ratio, for $60 \mathrm{~s}$ at $25 \mathrm{~mA}$ (Quorum Q150T, Quorum, Edwards, Hastings, UK).

The dielectric properties, such as relative permittivity $\left(\varepsilon_{r}\right)$ and dielectric loss $(\tan \delta)$, of the additively manufactured samples were determined by placing the cylindrical 3D printed test samples of $10 \mathrm{~mm}$ diameter and $4 \mathrm{~mm}$ thickness, in a $24 \mathrm{~mm} \mathrm{TE} \mathrm{m}_{01 \delta}$ cavity resonator (QWED, Warsaw, Poland), measuring the $\mathrm{Q}$ factor and the resonant frequency of the $\mathrm{TE}_{01 \delta}$ mode, connected to a Vector Network Analyser (VNA) (MS465B22, Anritsu, Japan) using coaxial cables [25]. The properties were calculated using QWED's proprietary software. Results of $\varepsilon_{r}, Q \times f$ and tan $\delta$ are reported as an average of three different printed samples, together with the standard deviation.

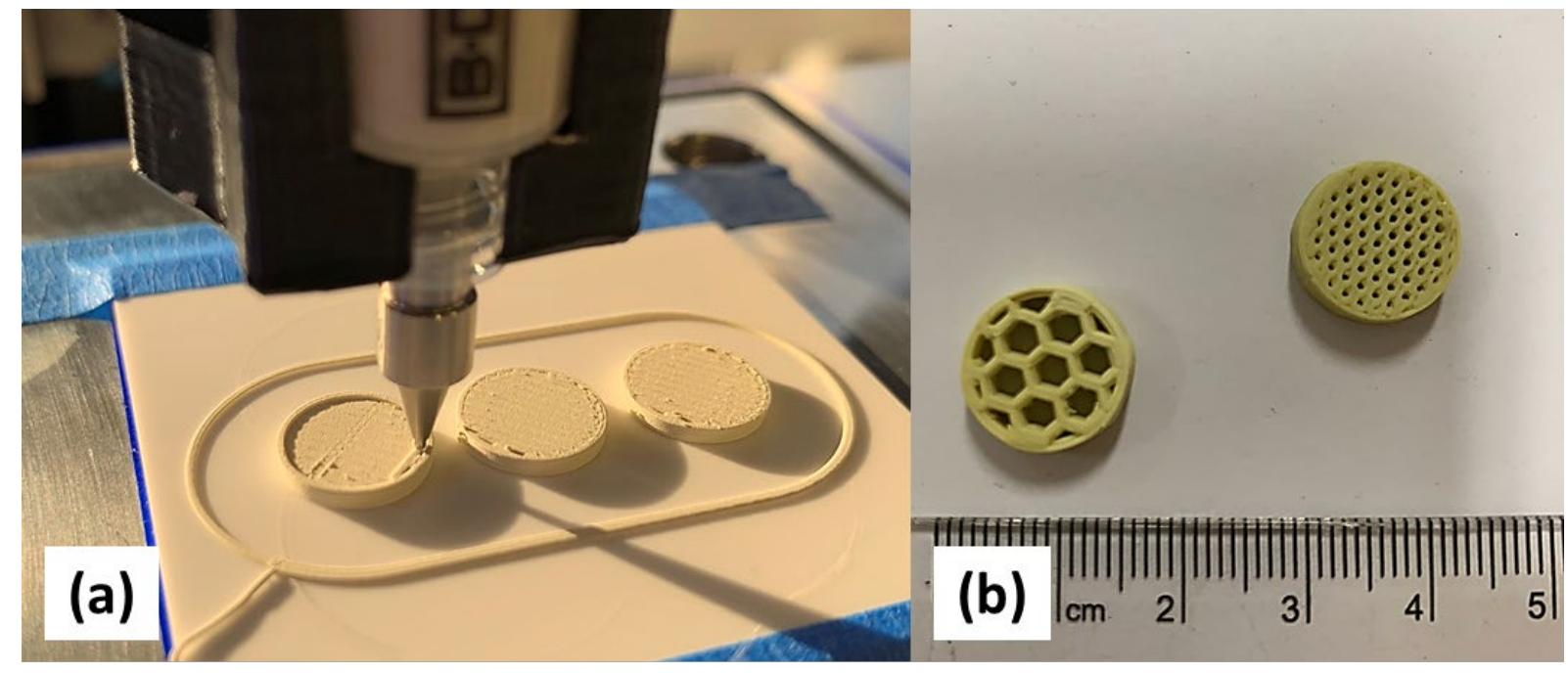

Figure 1-Photos of (a) direct ink writing of BMO test samples and (b) 3D printed and sintered samples with different infill densities. 


\section{RESULTS AND DISCUSSION}

\subsection{Raw material characterisation}

Figure 2 shows the particle size distribution of the purchased BMO powders as measured via laser diffraction. Measurements from three separate powder samples (Sample 1-3) revealed a multimodal distribution within the $0.9-10 \mu \mathrm{m}$ size range, with a size median at $D_{50}=4.34 \pm 0.8 \mu \mathrm{m}$. Knowledge of the particle size distribution is particularly useful for the preparation of the ceramic suspensions as it allows for better tuning of their rheological properties [26]. This is achieved through the effective control of the solid loading (amount of the ceramic filler within the ceramic colloidal suspension), the viscosity of the starting binder, together with calculating the correct amount of dispersant to be used, in order to achieve a stable colloidal suspension, making a printable paste for direct ink writing [2729]. Multi-modal particle distributions; as the powder that is used, are often preferred when making ceramic formulations for additive manufacturing, since the combination of big and small particles within the suspension, often exhibit a more desirable rheological behaviour such as high solid content and lower viscosity [30,31] and reduced shrinkage during drying [32], compared to unimodal distributions. Additionally, this has been found to have a positive effect with sintering, as the smaller particles are expected to fill in any intra-granular gaps formed in between the larger grains and lead to improved packing densification and mechanical properties [32-35]. 


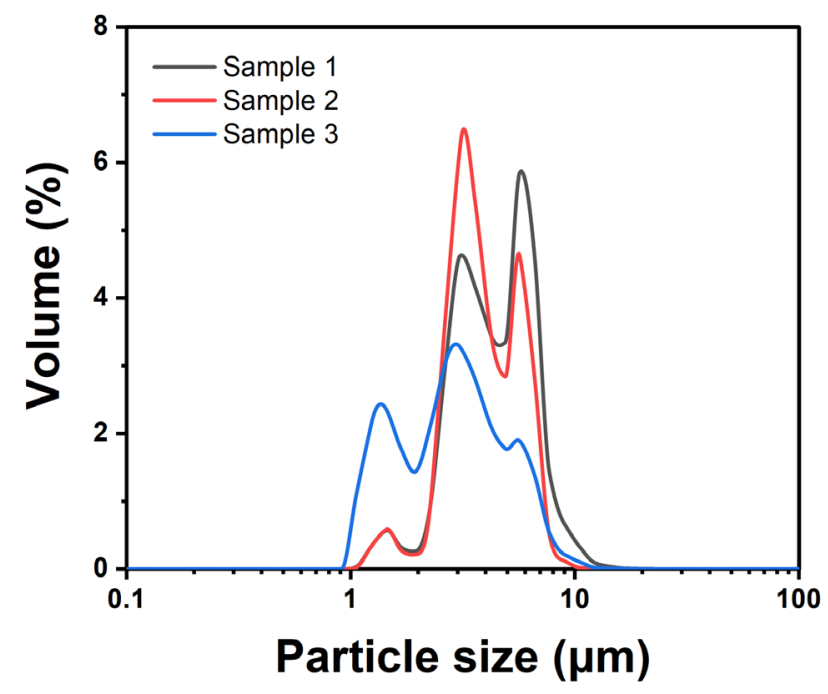

Figure 2 - Particle size distribution of the BMO powders measured via laser diffraction.

\subsection{X-Ray Diffraction}

Figure 3 shows the diffraction patterns of the as-purchased BMO powder and the 3D printed specimens sintered at $640-680^{\circ} \mathrm{C}$. The diffraction peaks from the as-received BMO powder were indexed to the coexistence of three phases: the monoclinic $\alpha-\mathrm{Bi}_{2} \mathrm{Mo}_{3} \mathrm{O}_{12}$ phase of the $\mathrm{P} 2{ }_{1} / \mathrm{m}$ group with lattice parameters $a=7.719 \AA, b=11.516 \AA, c=11.985 \AA, 6=115.4^{\circ}$ (ICDD PDF 21-0103), the monoclinic $\beta-\mathrm{Bi}_{2} \mathrm{Mo}_{2} \mathrm{O}_{9}$ phase of the $\mathrm{P} 2_{1} / \mathrm{m}$ space group, with lattice parameters $a=11.954 \AA, b=$ $10.81 \AA, c=11.89 \AA, 6=90^{\circ}$ (ICDD PDF 33-009), and the monoclinic $\gamma-\mathrm{Bi}_{2} \mathrm{MoO}_{6}$ phase of the $\mathrm{P} 2{ }_{1} / \mathrm{c}$ space group with lattice parameters $a=17.251 \AA, b=22.422 \AA, c=5.581 \AA, b=89.503^{\circ}$ (ICDD PDF 330208). The theoretical densities of all identified three-phases were calculated via XRD measured data: $\rho_{\alpha-B M O}=6.1 \mathrm{~g} / \mathrm{cm}^{3}, \rho_{6-B M O}=6.5 \mathrm{~g} / \mathrm{cm}^{3}$ and $\rho_{Y-B M O}=7.5 \mathrm{~g} / \mathrm{cm}^{3}$ accordingly.

The diffraction patterns collected from the 3D printed test specimens fired in the $640-660^{\circ}$ temperature region, were indexed to the monoclinic $\beta-\mathrm{Bi}_{2} \mathrm{Mo}_{2} \mathrm{O}_{9}$ single phase, with no traces of the $\alpha$ and $\gamma$ - phases being detected. $\beta-\mathrm{Bi}_{2} \mathrm{Mo}_{2} \mathrm{O}_{9}$, is the phase amongst the $\mathrm{Bi}_{2} \mathrm{O}_{3}-\mathrm{MoO}_{3}$ binary system with the highest theoretical $\varepsilon_{\mathrm{r}}$ of approximately 40 [36]. High $\varepsilon_{\mathrm{r}}$ values are desirable as they allow miniaturisation of telecommunication devices $[1,24,37]$. 
Finally, the diffraction peaks collected from the test specimens fired at $670^{\circ} \mathrm{C}$, were indexed to all three $\alpha-\mathrm{Bi}_{2} \mathrm{Mo}_{3} \mathrm{O}_{12}, \beta-\mathrm{Bi}_{2} \mathrm{Mo}_{2} \mathrm{O}_{9}$ and $\gamma-\mathrm{Bi}_{2} \mathrm{MoO}_{6}$ phases. The re-appearance of the $\alpha$ - phase is ascribed to the decomposition of the $\beta$ - phase to $\alpha$ - and $\gamma^{-}$, when the processing temperature exceeds $650^{\circ} \mathrm{C}$, as previously identified by several studies $[14,36]$. However, the temperatures at which phase evolution is taking place, cannot be accurately defined due to physical factors, such as the particle size [38], that directly affect the temperature at which these thermophysical activities take place.

The test samples fired at $670^{\circ} \mathrm{C}$ are expected to have reduced $\varepsilon_{r}$, as their effective permittivity $\left(\varepsilon_{\text {eff }}\right)$ will be determined by the collective performance of all three present BMO phases. The pure $\alpha$-BMO and $\gamma$-BMO phases have previously been measured with $\varepsilon_{r \alpha-B M O}=19$ and $\varepsilon_{r-B M O}=31$ [39], less than that of pure $\beta-\mathrm{Bi}_{2} \mathrm{Mo}_{2} \mathrm{O}_{9}$.

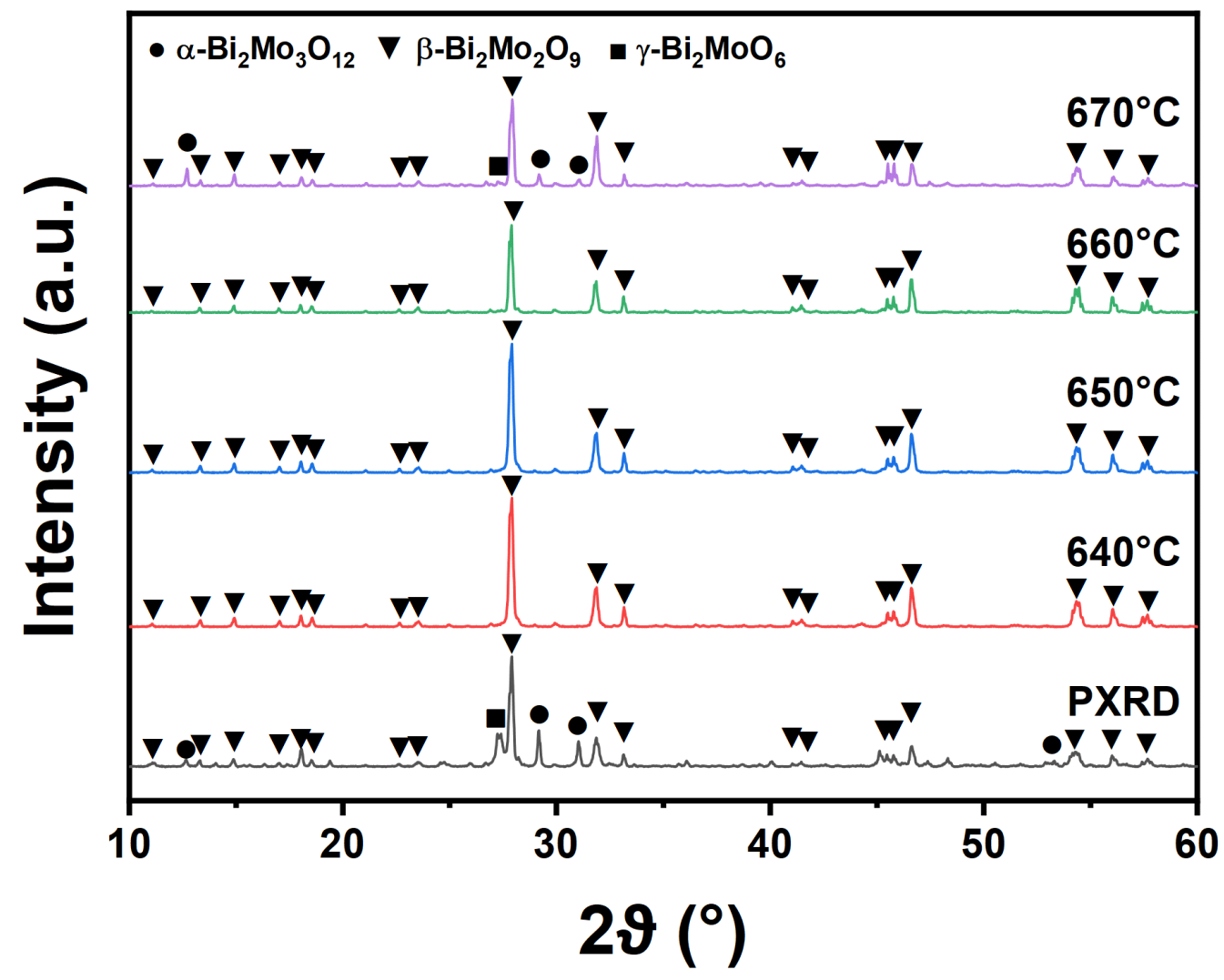

Figure $3-X R D$ patterns of the powder (PXRD) and $3 D$ printed samples sintered at $640-670^{\circ} \mathrm{C}$. 


\subsection{Microstructure}

Figure 4, contains a series of electron micrographs from both the surface and the polished crosssections of the 3D printed test specimens sintered at $640-670^{\circ} \mathrm{C}$. A progressive reduction in porosity with increasing temperature is evident, due to the grain growth mechanisms that take place during sintering. However, at $670^{\circ} \mathrm{C}$, larger pores can be seen in the cross-section (Figure $4 \mathrm{~h}$ ), possibly due to dissimilar grain growth mechanisms of the co-existing $\beta-\mathrm{Bi}_{2} \mathrm{Mo}_{2} \mathrm{O}_{9}$ and $\alpha-\mathrm{Bi}_{2} \mathrm{Mo}_{3} \mathrm{O}_{12}$ and $\gamma-\mathrm{Bi}_{2} \mathrm{MoO}_{6}$ introducing pores between the grains. In Figure $\mathbf{4 d}$, the existing grains have assumed an elongated/columnar structure, consistent with the remarks above. Such behaviour is expected to have a significant impact on microwave performance of the resulting parts, since porosity will effectively reduce $\varepsilon_{\mathrm{r}}$ and increase in $\tan \delta[12,40]$. $\tan \delta$ is greatly influenced by the presence of moisture within the ceramic bodies [41] which resides on the surface of internal pores. A greater level of porosity is therefore expected to accommodate greater amounts of moisture causing the $\tan \delta$ to increase.

With conventional densification approaches where pressure is also applied to the green bodies, sintering mechanisms would have the same effect throughout the green body, leading to an overall reduction of porosity. However, this is not the case when 3D printing is used to manufacture functional parts, as no additional pressure is applied, and higher levels of porosity exist. A number of processrelated limitations are likely to have an impact on the printed structure resulting in behaviour very different from what would normally be expected with conventional manufacturing. It is crucial therefore, to investigate the post-processing procedures required for the final parts to meet their expected performance.

Lower magnification images (Figure 4a-4l) reveal a number of air voids in between the printed layers of the test samples. These voids are caused by outgassing of the organic compounds in the ceramic paste during the thermal debinding stage. Aside from the intergranular porosity, interlayer porosity is detrimental to the MW properties of the ceramics but a significant reduction of interlayer porosity occurs as the sintering temperature is increased from $650^{\circ} \mathrm{C}$ to $660^{\circ} \mathrm{C}$. Higher sintering temperatures 
are expected to induce increased interdiffusion between the adjacent layers and thus minimise any existing air voids. Due to a combination of grain growth and the increased levels of porosity in the samples fired at $670^{\circ} \mathrm{C}$, it is impossible to identify any remaining air gaps between the layers of the 3D printed structure; as shown in Figure 41.
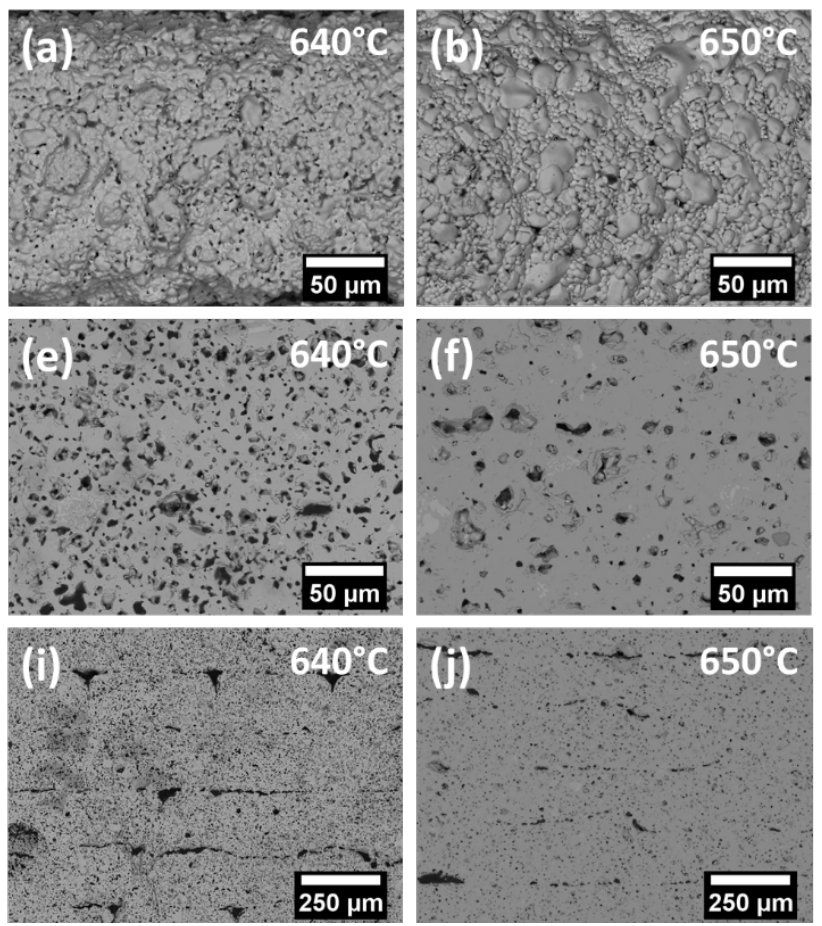
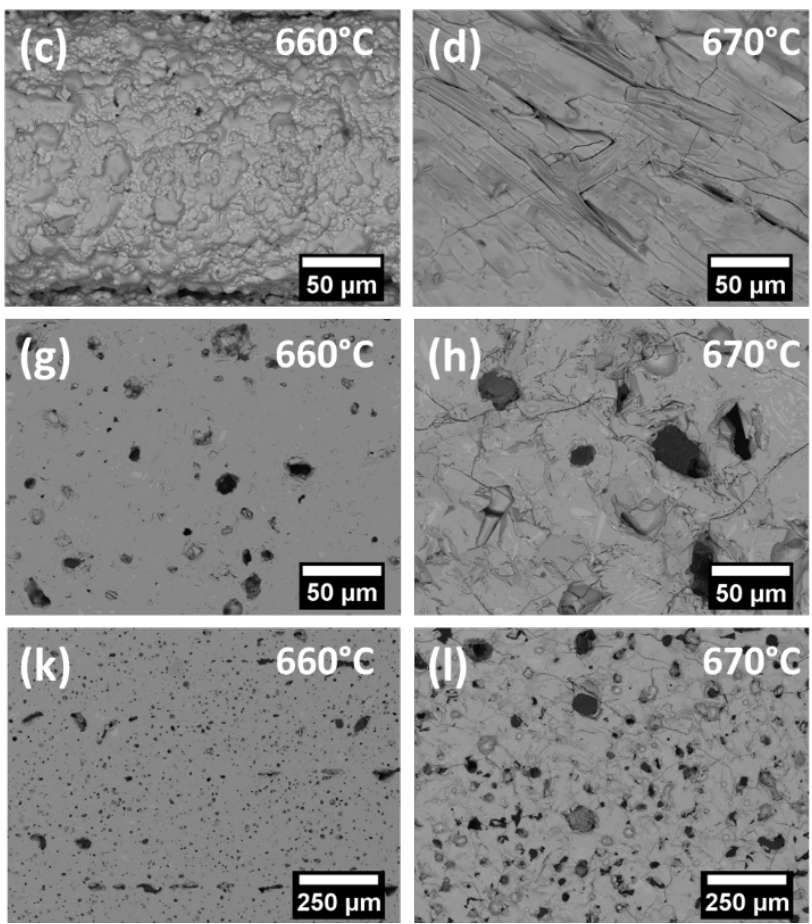

Figure 4 - Electron micrographs of $3 D$ printed and $B M O$ samples after sintering at $640-670{ }^{\circ} \mathrm{C}$. (ad) surface microstructure, $(e-h)$ polished cross-sections at 1000 times magnification and $(i-l)$, polished cross-sections at 200 times magnification.

\subsection{Microwave dielectric properties}

Figure 5 shows the microwave dielectric properties and densities from the 3D printed and sintered test samples, at $640-670^{\circ} \mathrm{C}$. $\varepsilon_{r}$ increases as a function of sintering temperature until $660^{\circ} \mathrm{C}$ where the highest a value of $\varepsilon_{r}=35.7 \pm 0.18$ is recorded. Above $660^{\circ} \mathrm{C}, \varepsilon_{r}$ exhibited a progressive reduction as shown in Figure $\mathbf{5 a}$. The behaviour of $\varepsilon_{r}$ as a function of sintering temperature is in agreement with the density measurements shown in Figure $\mathbf{5 b}$. The highest density of $\rho=6.03 \pm 0.01 \mathrm{~g} / \mathrm{cm}^{3}$; corresponding to $\rho_{\mathrm{r}} \approx 93 \%$ relative density $\left(\rho_{\mathrm{r}}\right)$, was also recorded at $660^{\circ} \mathrm{C}$. Despite the $\rho_{\mathrm{r}}(\approx 93 \%)$ 
being below $100 \%, \varepsilon_{r}$ of the 3D printed samples are comparable to those of conventionally sintered samples previously reported in the literature $[11,15]$.
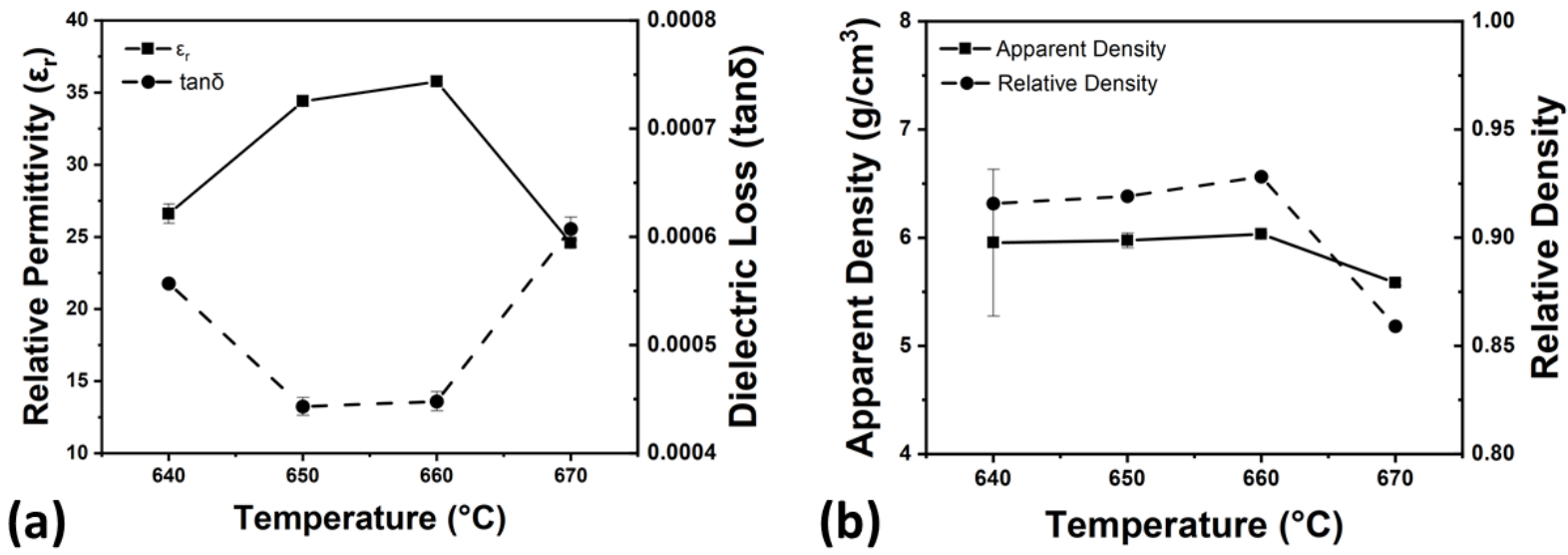

Figure 5 - The effect of sintering temperature on the microwave dielectric properties of 3D printed $B M O$ ceramic samples: (a) relative permittivity ( $\left.\varepsilon_{r}\right)$ and dielectric loss (tan $\left.\delta\right)$, (b) apparent and relative density.

Finally, $Q \times f$ values of the 3D printed BMO samples showed an increase from $12,487 \pm 337 \mathrm{GHz}$ to $14,928 \pm 591 \mathrm{GHz}$ as a function of sintering temperature, from 640 to $660^{\circ} \mathrm{C}$, which is higher than previously reported values for pure $\beta-\mathrm{Bi}_{2} \mathrm{Mo}_{2} \mathrm{O}_{9}[16]$. However, $Q \times f$ was reduced to $12,496 \pm 63 \mathrm{GHz}$ for samples sintered at $670^{\circ} \mathrm{C}$, as shown in Figure 6. Qxf is known is not only sensitive to intrinisic factors such as inharmonic lattice vibrations but also grain size, grain boundaries and macroscopic defects suchs as microcracks and porosity [11,42-44]. The increase in $Q \times f$ below $660^{\circ} \mathrm{C}$ is ascribed to the reduction of porosity and associated grain growth. The 3D printed BMO ceramics fabricated in this paper exhibit low dielectric loss values of $\tan \delta=0.0004 \pm 0.0009$ recorded at $650-660^{\circ} \mathrm{C}$, which is an order of magnitude superior to materials currently used in the LTCC telecommunication industry $[45,46]$. 


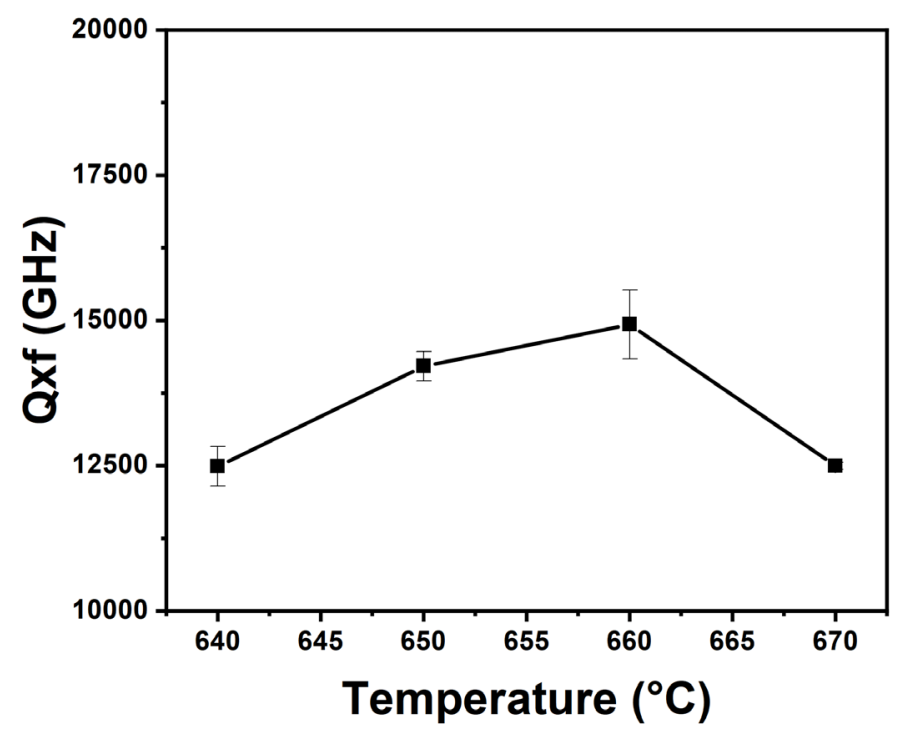

Figure 6 - The effect of sintering temperature on the quality factor (Qxf) of 3D printed BMO ceramic samples.

Table 1, summarises all measured MW dielectric and physical properties of the BMO samples, produced via the direct ink writing 3D printing process. All manufactured and characterised specimens in this paper, have shown excellent repeatability in terms of their microwave dielectric properties with $\sigma\left(\varepsilon_{r}\right)<0.5 \%$ and $\sigma(Q \times f)<4 \%$ when sintered at $660^{\circ} \mathrm{C}$. This further suggests the very good potential of the direct ink writing to be used for manufacturing ceramic substrates for telecommunication devices.

Table 1 - The sintering temperatures, microwave dielectric properties and densities of the additively manufactured BMO ceramic samples.

\begin{tabular}{cccccc}
\hline $\begin{array}{c}\text { Temperature } \\
\left({ }^{\circ} \mathrm{C}\right)\end{array}$ & $\varepsilon_{r}$ & $\tan \delta$ & Density $\left(\mathrm{g} / \mathrm{cm}^{3}\right)$ & $\begin{array}{c}\text { Relative } \\
\text { Density }\end{array}$ & Qxf (GHz) \\
\hline 640 & $26.6 \pm 0.66$ & $0.0006 \pm 0.000001$ & $5.95 \pm 0.60$ & 0.92 & $12487 \pm 337$ \\
650 & $34.3 \pm 0.19$ & $0.0004 \pm 0.000008$ & $5.97 \pm 0.07$ & 0.92 & $14210 \pm 256$ \\
660 & $35.7 \pm 0.18$ & $0.0004 \pm 0.000009$ & $6.03 \pm 0.01$ & 0.93 & $14928 \pm 591$ \\
670 & $24.5 \pm 0.28$ & $0.0006 \pm 0.000011$ & $5.58 \pm 0.03$ & 0.86 & $12496 \pm 63$ \\
\hline
\end{tabular}




\section{CONCLUSIONS}

Direct ink writing (DIW), a flexible 3D printing process of the material extrusion process category, has been employed to produce test samples of Bismuth Molybdenum Oxide (BMO), a low sintering temperature microwave ceramic material, suitable for wireless telecommunication devices. The result of post processing to the physical, microstructural and microwave dielectric properties of the 3D printed parts, are being reported for the first time.

It was shown that direct ink writing is a promising candidate for shaping advanced ceramic components with excellent repeatability; $\sigma\left(\varepsilon_{r}\right)<0.5 \%$ and $\sigma(Q x f)<4 \%$, and very low dielectric loss. The following points summarise the major conclusions arising from this study:

- Stable and defect-free BMO green bodies can be produced using a $0.5 \mathrm{~mm}$ conical nozzle, 0.2 $\mathrm{mm}$ layer thickness, $5 \mathrm{~mm} / \mathrm{s}$ printing speed and $0.45 \mathrm{~mm}$ hatch spacing.

- Optimum post processing conditions for achieving the highest MW dielectric properties, was achieved while sintering the $\mathrm{BMO}$ green bodies at $660^{\circ} \mathrm{C}$ for 2 hours in static air. This resulted in a relative permittivity of $\varepsilon_{r}=35.7$, dielectric loss of $\tan \delta=0.0004$ and quality factor $Q \times f=$ $14,928 \mathrm{GHz}$.

- Sintering at $660^{\circ} \mathrm{C}$ for 2 hours favoured the reduction of both intergranular and interlaminar porosity; thereby improving the relative permittivity, dielectric loss and quality factor of the 3D printed test samples.

- Processing temperatures above $660^{\circ} \mathrm{C}$ had a negative impact on $\mathrm{MW}$ properties due to phase transformations that further promoted porosity due to a mismatch in grain growth regime. 


\section{ACKNOWLEDGEMENTS}

This work was funded by EPSRC research grant 'SYMETA' (EP/N010493/1). The authors would like to thank the technicians of the Loughborough Materials Characterisation Centre (LMCC) for their help with the analytical equipment.

\section{Declaration of competing interests}

The authors declare that they have no known competing financial interests or personal relationships that could have appeared to influence the work reported in this paper. 


\section{REFERENCES}

[1] I.M. Reaney, D. Iddles, Microwave dielectric ceramics for resonators and filters in mobile phone networks, J. Am. Ceram. Soc. 89 (2006) 2063-2072. doi:10.1111/j.1551-2916.2006.01025.X.

[2] Z. Tan, K. Song, H.B. Bafrooei, B. Liu, J. Wu, J. Xu, H. Lin, D. Wang, The effects of TiO2 addition on microwave dielectric properties of Y3MgAl3SiO12 ceramic for 5G application, Ceram. Int. 46 (2020) 15665-15669. doi:10.1016/j.ceramint.2020.03.116.

[3] Z. Song, K. Song, B. Liu, P. Zheng, H. Barzegar Bafrooei, W. Su, H. Lin, F. Shi, D. Wang, I.M. Reaney, Temperature-dependent dielectric and Raman spectra and microwave dielectric properties of gehlenite-type Ca2Al2SiO7 ceramics, Int. J. Appl. Ceram. Technol. 17 (2020) 771777. doi:10.1111/ijac.13414.

[4] Q. Lin, K. Song, B. Liu, H.B. Bafrooei, D. Zhou, W. Su, F. Shi, D. Wang, H. Lin, I. M.Reaney, Vibrational spectroscopy and microwave dielectric properties of $\mathrm{AY} 2 \mathrm{Si} 3 \mathrm{O} 10$ ( $\mathrm{A}=\mathrm{Sr}, \mathrm{Ba})$ ceramics for 5G applications, Ceram. Int. 46 (2020) 1171-1177. doi:10.1016/j.ceramint.2019.09.086.

[5] D. Zhou, L.X. Pang, D. Wang, I.M. Reaney, BiVO4 based high: K microwave dielectric materials: A review, J. Mater. Chem. C. 6 (2018) 9290-9313. doi:10.1039/c8tc02260g.

[6] D. Zhou, L.X. Pang, D.W. Wang, C. Li, B.B. Jin, I.M. Reaney, High permittivity and low loss microwave dielectrics suitable for $5 \mathrm{G}$ resonators and low temperature co-fired ceramic architecture, J. Mater. Chem. C. 5 (2017) 10094-10098. doi:10.1039/c7tc03623j.

[7] D. Zhou, D. Guo, W.B. Li, L.X. Pang, X. Yao, D.W. Wang, I.M. Reaney, Novel temperature stable high-: $\epsilon$ r microwave dielectrics in the Bi2O3-TiO2-V2O5 system, J. Mater. Chem. C. 4 (2016) 5357-5362. doi:10.1039/c6tc01431c.

[8] S.Z. Hao, D. Zhou, F. Hussain, W.F. Liu, J.Z. Su, D.W. Wang, Q.P. Wang, Z.M. Qi, C. Singh, S. 
Trukhanov, Structure, spectral analysis and microwave dielectric properties of novel $\mathrm{x}(\mathrm{NaBi}) 0.5 \mathrm{MoO} 4-(1-\mathrm{x}) \mathrm{Bi} 2 / 3 \mathrm{MoO} 4(\mathrm{x}=0.2 \sim 0.8)$ ceramics with low sintering temperatures, $\mathrm{J}$. Eur. Ceram. Soc. 40 (2020) 3569-3576. doi:10.1016/j.jeurceramsoc.2020.03.074.

[9] H.H. Guo, D. Zhou, W.F. Liu, L.X. Pang, D.W. Wang, J.Z. Su, Z.M. Qi, Microwave dielectric properties of temperature-stable zircon-type (Bi, Ce)VO4 solid solution ceramics, J. Am. Ceram. Soc. 103 (2020) 423-431. doi:10.1111/jace.16759.

[10] D. Zhou, L.X. Pang, D.W. Wang, Z.M. Qi, I.M. Reaney, High Quality Factor, Ultralow Sintering Temperature Li6B409 Microwave Dielectric Ceramics with Ultralow Density for Antenna $\begin{array}{lllllll}\text { Substrates, ACS Sustain. Chem. } & \text { Eng. } 6 \quad \text { (2018) }\end{array}$ doi:10.1021/acssuschemeng.8b02755.

[11] D. Wang, B. Siame, S. Zhang, G. Wang, X. Ju, J. Li, Z. Lu, Y. Vardaxoglou, W. Whittow, D. Cadman, S. Sun, D. Zhou, K. Song, I.M. Reaney, Direct Integration of Cold Sintered, Temperature-Stable Bi2Mo2O9-K2MoO4 Ceramics on Printed Circuit Boards for Satellite Navigation Antennas, J. Eur. Ceram. Soc. (2020) 0-1. doi:10.1016/j.jeurceramsoc.2020.04.025.

[12] D. Wang, J. Chen, G. Wang, Z. Lu, S. Sun, J. Li, J. Jiang, D. Zhou, K. Song, I.M. Reaney, Cold sintered LiMgPO4 based composites for low temperature co-fired ceramic (LTCC), J. Am. Ceram. Soc. (2020). doi:doi:10.1111/jace.17320.

[13] R. Muhammad, Y. Iqbal, C.R. Rambo, H. Khan, Research trends in microwave dielectrics and factors affecting their properties: A review, Int. J. Mater. Res. 105 (2014) 431-439. doi:10.3139/146.111044.

[14] M. Egashira, K. Matsuo, S. Kagawa, T. Seiyama, Phase diagram of the system Bi2O3MoO3, J. Catal. 58 (1979) 409-418. doi:10.1016/0021-9517(79)90279-3.

[15] D. Zhou, H. Wang, X. Yao, L.-X. Pang, Microwave Dielectric Properties of Low Temperature Firing $\mathrm{Bi}_{2} \mathrm{Mo}_{2} \mathrm{O}_{9}$ Ceramic, J. Am. Ceram. Soc. 91 (2008) 3419-3422. doi:10.1111/j.1551- 
2916.2008.02596.x.

[16] D. Zhou, H. Wang, L.X. Pang, C.A. Randall, X. Yao, Bi 20 3-MoO 3 Binary system: An alternative ultralow sintering temperature microwave dielectric, J. Am. Ceram. Soc. 92 (2009) 2242-2246. doi:10.1111/j.1551-2916.2009.03185.x.

[17] Z. Chen, Z. Li, J. Li, C. Liu, C. Lao, Y. Fu, C. Liu, Y. Li, P. Wang, Y. He, 3D printing of ceramics: A review, J. Eur. Ceram. Soc. 39 (2019) 661-687. doi:10.1016/j.jeurceramsoc.2018.11.013.

[18] J. Deckers, J. Vleugels, J. Kruth, Additive Manufacturing of Ceramics : A Review, J. Ceram. Sci. Technol. 260 (2014) 245-260. doi:10.4416/JCST2014-00032.

[19] A. Goulas, S. Zhang, J.R. Mcghee, D.A. Cadman, W.G. Whittow, J.C.V. Yiannis, D.S. Engstrøm, Fused filament fabrication of functionally graded polymer composites with variable relative permittivity for microwave devices, Mater. Des. $193 \quad$ (2020) 108871. doi:10.1016/j.matdes.2020.108871.

[20] A. Goulas, G. Chi-Tangyie, D. Wang, S. Zhang, A. Ketharam, B. Vaidhyanathan, I.M. Reaney, D.A. Cadman, W.G. Whittow, J. (Yiannis) C. Vardaxoglou, D.S. Engstrøm, Additively manufactured ultra-low sintering temperature, low loss Ag2Mo2O7 ceramic substrates, J. Eur. Ceram. Soc. 41 (2020) 394-401. doi:10.1016/j.jeurceramsoc.2020.08.031.

[21] J. Raynaud, V. Pateloup, M. Bernard, D. Gourdonnaud, D. Passerieux, D. Cros, V. Madrangeas, T. Chartier, Hybridization of additive manufacturing processes to build ceramic/metal parts: Example of LTCC, J. Eur. Ceram. Soc. 40 (2020) 759-767. doi:10.1016/j.jeurceramsoc.2019.10.019.

[22] R. Gheisari, H. Chamberlain, G. Chi-Tangyie, S. Zhang, A. Goulas, C.K. Lee, T. Whittaker, D. Wang, A. Ketharam, A. Ghosh, B. Vaidhyanathan, W. Whittow, D. Cadman, Y.C. Vardaxoglou, I.M. Reaney, D.S. Engstrøm, Multi-material additive manufacturing of low sintering temperature Bi2Mo2O9 ceramics with Ag floating electrodes by selective laser burnout, Virtual 
Phys. Prototyp. 15 (2020) 133-147. doi:10.1080/17452759.2019.1708026.

[23] M. Väätäjä, H. Kähäri, J. Juuti, H. Jantunen, Li2MoO4-based composite ceramics fabricated from temperature- and atmosphere-sensitive $\mathrm{MnZn}$ ferrite at room temperature, J. Am. Ceram. Soc. 100 (2017) 3626-3635. doi:10.1111/jace.14914.

[24] J. Perelaer, P.J. Smith, D. Mager, D. Soltman, S.K. Volkman, V. Subramanian, J.G. Korvink, U.S. Schubert, Printed electronics: the challenges involved in printing devices, interconnects, and contacts based on inorganic materials, J. Mater. Chem. 20 (2010) 8446. doi:10.1039/c0jm00264j.

[25] C. Lee, J. McGhee, C. Tsipogiannis, S. Zhang, D. Cadman, A. Goulas, T. Whittaker, R. Gheisari, D. Engstrom, J. (Yiannis) Vardaxoglou, W. Whittow, Evaluation of Microwave Characterization Methods for Additively Manufactured Materials, Designs. 3 (2019). doi:10.3390/designs3040047.

[26] J. Graczyk, W.G. Gleißle, H. Buggisch, Rheological Investigation of Suspensions and Ceramic Pastes: Characterization of Extrusion Properties, KONA Powder Part. J. 11 (1993) 125-137. doi:10.14356/kona.1993015.

[27] H. Sarraf, Z. Qian, L. Škarpová, B. Wang, R. Herbig, M. Maryška, L. Bartovska, J. Havrda, B. Anvari, Direct Probing of Dispersion Quality of ZrO2 Nanoparticles Coated by Polyelectrolyte at Different Concentrated Suspensions, Nanoscale Res. Lett. 10 (2015) 1-14. doi:10.1186/s11671015-1157-z.

[28] H. Sarraf, A. Sabet, R. Herbig, J. Havrda, V. Hulínský, M. Maryšká, Advanced colloidal techniques for characterization of the effect of electrosteric dispersant on the colloidal stability of nanocrystalline ZrO 2 suspension (Journal of the Ceramic Society of Japan (2009) 117:3 (302307)), J. Ceram. Soc. Japan. 117 (2009) 542. doi:10.2109/jcersj2.117.542.

[29] X. Liu, Y. Huang, J. Yang, Effect of rheological properties of the suspension on the mechanical 
strength of Al2O3-ZrO2 composites prepared by gelcasting, Ceram. Int. 28 (2002) 159-164. doi:10.1016/S0272-8842(01)00072-4.

[30] G. Tarì, J.M.F. Ferreira, A.T. Fonseca, O. Lyckfeldt, Influence of particle size distribution on colloidal processing of alumina, J. Eur. Ceram. Soc. 18 (1998) 249-253. doi:10.1016/s09552219(97)00113-1.

[31] C. Chang, R.L. Powell, Effect of particle size distributions on the rheology of concentrated bimodal suspensions, J. Rheol. (N. Y. N. Y). 38 (1994) 85-98. doi:10.1122/1.550497.

[32] K. Rane, M. Strano, A comprehensive review of extrusion-based additive manufacturing processes for rapid production of metallic and ceramic parts, Adv. Manuf. 7 (2019) 155-173. doi:10.1007/s40436-019-00253-6.

[33] B. Finke, J. Hesselbach, A. Schütt, M. Tidau, B. Hampel, M. Schilling, A. Kwade, C. Schilde, Influence of formulation parameters on the freeform extrusion process of ceramic pastes and resulting product properties, Addit. Manuf. $32 \quad$ (2020) 101005. doi:10.1016/j.addma.2019.101005.

[34] Y. Lakhdar, C. Tuck, J. Binner, A. Terry, R. Goodridge, Additive Manufacturing of Advanced Ceramic Materials, Prog. Mater. Sci. 116 (2020) 100736. doi:10.1016/j.pmatsci.2020.100736.

[35] R.L. Walton, M.A. Fanton, R.J. Meyer, G.L. Messing, Dispersion and rheology for direct writing lead-based piezoelectric ceramic pastes with anisotropic template particles, J. Am. Ceram. Soc. 103 (2020) 6157-6168. doi:10.1111/jace.17350.

[36] D. Zhou, H. Wang, X. Yao, L.-X. Pang, Microwave Dielectric Properties of Low Temperature Firing Bi 2 Mo 2 O 9 Ceramic, J. Am. Ceram. Soc. 91 (2008) 3419-3422. doi:10.1111/j.15512916.2008.02596.x.

[37] M.T. Sebastian, R. Ubic, H. Jantunen, Low-loss dielectric ceramic materials and their properties, Int. Mater. Rev. 60 (2015) 392-412. doi:10.1179/1743280415Y.0000000007. 
[38] Z.X. Cui, M.Z. Zhao, W.P. Lai, Y.Q. Xue, Thermodynamics of size effect on phase transition temperatures of dispersed phases, J. Phys. Chem. C. 115 (2011) 22796-22803. doi:10.1021/jp2067364.

[39] J. Yang, Z. Ling, Y. Zhuang, Bi2MoO6 dielectric thin films fabricated by thermal oxidation of Bi/Mo thin films at ultra-low temperature, J. Mater. Sci. Mater. Electron. 25 (2014) 1856-1862. doi:10.1007/s10854-014-1810-9.

[40] D. Zhou, J. Li, L.X. Pang, G.H. Chen, Z.M. Qi, D.W. Wang, I.M. Reaney, Crystal Structure, Infrared Spectra, and Microwave Dielectric Properties of Temperature-Stable Zircon-Type (Y,Bi)VO4 Solid-Solution Ceramics, ACS Omega. 1 (2016) 963-970. doi:10.1021/acsomega.6b00274.

[41] M.T. Sebastian, M.A.S. Silva, A.S.B. Sombra, Measurement of Microwave Dielectric Properties and Factors Affecting Them, Microw. Mater. Appl. 2V Set. (2017) 1-51. doi:doi:10.1002/9781119208549.ch1.

[42] S.J. Penn, N.M. Alford, A. Templeton, X. Wang, M. Xu, M. Reece, K. Schrapel, Effect of Porosity and Grain Size on the Microwave Dielectric Properties of Sintered Alumina, J. Am. Ceram. Soc. 80 (2005) 1885-1888. doi:10.1111/j.1151-2916.1997.tb03066.x.

[43] D. Wang, S. Zhang, G. Wang, Y. Vardaxoglou, W. Whittow, D. Cadman, D. Zhou, K. Song, I.M. Reaney, Cold sintered CaTiO3-K2MoO4 microwave dielectric ceramics for integrated microstrip patch antennas, Appl. Mater. Today. 18 (2020) 100519. doi:10.1016/j.apmt.2019.100519.

[44] D. Wang, D. Zhou, K. Song, A. Feteira, C.A. Randall, I.M. Reaney, Cold-Sintered COG Multilayer Ceramic Capacitors, Adv. Electron. Mater. 5 (2019) 1-5. doi:10.1002/aelm.201900025.

[45] M.T. Sebastian, H. Jantunen, Low loss dielectric materials for LTCC applications: a review, Int. Mater. Rev. 53 (2008) 57-90. doi:10.1179/174328008X277524.

[46] A. Khan, R. Nema, Analysis of Five Different Dielectric Substrates on Microstrip Patch Antenna, Int. J. Comput. Appl. 55 (2012) 40-47. doi:10.5120/8826-2905. 